\title{
Canadian credentialing guidelines for colonoscopy
}

\author{
Joseph Romagnuolo MD FRCPC FASGE MScEpid ${ }^{1}$, Robert Enns MD FRCPC ${ }^{2}$, Terry Ponich MD FRCPC ${ }^{3}$, \\ Jonathon Springer MD FRCPC ${ }^{4}$, David Armstrong MA MB BChir FRCPC FRCP(UK) AGAF FACG ${ }^{5}$, \\ Alan N Barkun MD CM MSc FRCPC 6
}

\begin{abstract}
A series of credentialing guidelines for gastrointestinal endoscopic procedures performed in the management of adult patients has been developed by the Canadian Association of Gastroenterology (CAG) Endoscopy Committee, approved by the Clinical Affairs Committee, and reviewed and endorsed by the Executive Board. In the present article, the CAG suggests specific guidelines for credentialing colonoscopy. It is intended to be read in conjunction with the introductory article that outlines the principles of credentialing (1).

The CAG does not credential individuals for colonoscopy; that is the responsibility of the endoscopist's local institution or facility. The purpose of these guidelines is to provide a framework that will allow organizations to assess the training and competence of applicants to perform colonoscopy as part of the credentialing process for the granting of privileges.

Colonoscopy is performed to visualize the colonic mucosa, and can be both a diagnostic and therapeutic procedure; it requires the passage of a specialized endoscope - a colonoscope - via the anus or a colostomy to the cecum and, in some cases, to the terminal ileum. The purpose of the procedure is to document any abnormalities, to take biopsies and perform photographic documentation when appropriate, to remove polyps, or to perform therapy such as stricture dilation or hemostasis, if necessary, while minimizing procedure-related risks such as excessive sedation, cardiorespiratory compromise, bleeding and colonic perforation.
\end{abstract}

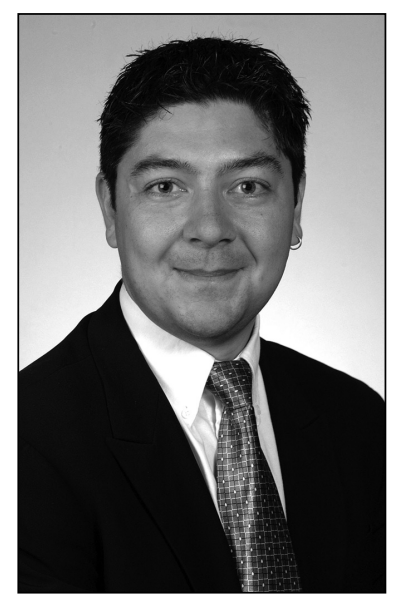

Dr Joseph Romagnuolo underutilization of colonoscopy for appropriate indications has also been reported. One survey of 168 internal medicine residents found that only $29 \%$ of residents recommended colonoscopy after a positive fecal occult blood test (7).

\section{TECHNICAL ASPECTS \\ Technical skills}

The credentialing criteria discussed in these guidelines have been evaluated with respect to colonoscopy in adult patients aged 18 years or older. The basic principles of credentialing also apply to colonoscopy by pediatric gastroenterologists in children, but the absolute numbers of procedures required to achieve and maintain competence may differ; guidance on credentialing for pediatric endoscopy is, therefore, considered to be the responsibility of the North American Society for Pediatric Gastroenterology, Hepatology and Nutrition.

Minimum number of procedures: The number

COGNITIVE ASPECTS
Appropriate indications
Knowledge of appropriate contraindications and indications
for colonoscopy, and the application of appropriate screening
and surveillance intervals, is essential. Appropriate indications
for colonoscopy, recommended by the American Society for
Gastrointestinal Endoscopy (ASGE) and the U.S. Multi-
Society Task Force on Colorectal Cancer, are shown in Table 1
(2). An indication should be documented for each procedure,
and if it is a nonstandard indication, it should be justified in
the documentation (3). Studies have shown that when
colonoscopy is performed for appropriate reasons, significantly
more clinically relevant diagnoses are made (4-6). However,
of procedures completed is currently the only objective measure that is available to assess competence upon completion of training and subsequently, in practice, to document maintenance of competence. Other measures are clearly important and relevant, but they are difficult to assess because there are currently no objective measures of their magnitude or effect. The most recent recommendation from the ASGE and the American College of Gastroenterology, is that 140 supervised, 'hands-on' colonoscopies should be considered as the competency threshold (ie, the threshold at which the technical component of competency should begin to be assessed) $(8,9)$. Performance of a specific, predefined number of procedures does not guarantee competence in colonoscopy (10-12), and a practitioner's technical competence should be assessed on an individual basis. The Gastroenterological Society of Australia recommends that at least 100 of the training colonoscopies should be complete (ie, at least to the cecum and preferably into the ileum), and completed without assistance (13).

Withdrawal times: A measurement of withdrawal time (the time from intubation of the cecum until withdrawal of the colonoscope from the anus) can be used as a quality indicator, because it has been correlated with adenoma detection rate $(3,14,15)$. A mean withdrawal time of 6 min to 7 min or longer

\footnotetext{
${ }^{1}$ Division of Gastroenterology and Hepatology, Medical University of South Carolina, Charleston, South Carolina, USA; ${ }^{2}$ Division of

Gastroenterology, University of British Columbia, Vancouver, British Columbia; 3 Division of Gastroenterology, University of Western Ontario,

London; ${ }^{4}$ St Joseph's Health Centre, Toronto; ${ }^{5}$ Division of Gastroenterology, McMaster University, Hamilton, Ontario; ${ }^{6}$ Division of

Gastroenterology, McGill University, Montreal, Quebec

Correspondence: Dr David Armstrong, Division of Gastroenterology, Health Sciences Centre 2F55, McMaster University Medical Centre,

1200 Main Street West, Hamilton, Ontario L8N 325. Telephone 905-521-2100 ext 76404, fax 905-523-6048, e-mail armstro@mcmaster.ca Received for publication September 6, 2007. Accepted September 7, 2007
} 


\begin{tabular}{l} 
TABLE 1 \\
Indications for colonoscopy \\
\hline - Evaluation, by barium enema or other imaging study, of an abnormality \\
that is likely to be clinically significant, such as a filling defect or \\
stricture \\
- Evaluation of unexplained gastrointestinal bleeding \\
- Unexplained iron deficiency anemia \\
- Screening and surveillance for colonic neoplasia \\
- Chronic inflammatory bowel disease of the colon, if a more precise \\
diagnosis or determination of the extent of activity of disease will \\
influence immediate management \\
- Clinically significant diarrhea of unexplained origin \\
- Intraoperative identification of a lesion not apparent at surgery \\
(eg, polypectomy site or location of a bleeding site) \\
- Treatment of bleeding from lesions such as vascular malformation, \\
ulceration, neoplasia and polypectomy sites (eg, electrocoagulation, \\
heater probe, laser or injection therapy) \\
- Foreign body removal \\
- Excision of a colonic polyp \\
- Decompression of acute nontoxic megacolon or sigmoid volvulus \\
- Balloon dilation of stenotic lesions (eg, anastomotic strictures) \\
- Palliative treatment of stenosing or bleeding neoplasms (eg, laser, \\
electrocoagulation and stenting) \\
- Marking a neoplasm for localization \\
\hline
\end{tabular}

Adapted with permission from reference 2

has been associated with a higher detection rate of adenomas $(3,14,15)$. In one study $(16)$, practitioners who had withdrawal times longer than $6 \mathrm{~min}$ had a detection rate for advanced neoplasia of $6.4 \%$, compared with $2.6 \%$ for practitioners who averaged shorter than 6 min of withdrawal time. Some studies may have been confounded by the extra time needed to remove any polyps found on withdrawal (14); however, more recent studies $(16,17)$ have reported lower polyp detection rates for endoscopists who had shorter withdrawal times during 'negative' colonoscopies (ie, procedures during which no polyps were detected). In the study, the median withdrawal time was $6.3 \mathrm{~min}$, while the median polyp detection rate was associated with a withdrawal time of $6.7 \mathrm{~min}$. Although endoscopists with a polyp detection rate at or above the 90th percentile had a mean withdrawal time of 11.9 min or longer, the authors proposed that the withdrawal time should be at least $7 \mathrm{~min}$ $(17,18)$.

Documentation of an individual's mean withdrawal time during negative colonoscopies may be useful in assessing the quality of endoscopic practice for those practitioners who report unexpectedly low or high polyp detection rates. However, it is important to note that standard withdrawal times are not necessarily applicable in individual cases, because differences in colon length, quality of colon preparation and the degree of prominence of haustral markings affect the withdrawal time required to examine the colon adequately (3).

Time to completion: It has been suggested that a mean procedure duration of $30 \mathrm{~min}$ is reasonable to permit completion of an adequate colonoscopy (10), although the precise time varies, depending on whether the studies have documented the total procedural time or the 'anus-to-cecum' time. In general, shorter procedural times are preferred to minimize patient discomfort, sedation requirements and costs, while recognizing that withdrawal times should be at least 6 min to
$7 \mathrm{~min}$, as discussed above. Furthermore, the speed of insertion needs to balance the trade-off between efficiency in resource utilization on the one hand, and accuracy and patient comfort on the other hand. If the insertion is too rapid, it may reduce the accuracy of lesion detection while increasing patient discomfort, the need for sedation and sedation-related complications.

Generally, the duration of the procedure diminishes with greater training and experience $(12,19,20)$. Studies $(12,20,21)$ report that the median time to the cecum is approximately $15 \mathrm{~min}$ to $25 \mathrm{~min}$ for trainees, compared with $7 \mathrm{~min}$ to $20 \mathrm{~min}$ for supervisors.

\section{Success rates}

Cecal intubation rates: Cecal intubation rates have commonly been used as a marker for 'colonoscopy completion'. Competent colonoscopists should be able to intubate the cecum in at least $85 \%$ to $90 \%$ of all cases $(3,13,22)$ and in at least $95 \%$ of cases when the indication is for screening in a healthy adult (3). Cecal intubation rates ranging from $76 \%$ to $99 \%$ have been reported $(21,23-25)$. The differences in intubation rates may be attributable, in part, to the duration and intensity of the endoscopists' training, because family physician colonoscopists have reported lower cecal intubation rates of $54 \%$ to $85 \%$ (26-28). Cecal intubation rates improve with increasing experience, as measured by the total number of procedures performed $(10-12,29,30)$. It has also been suggested that success rates are greater for endoscopists who perform more procedures annually (31), particularly in the early years of their practice (32). The fact that success rates are higher for endoscopists who perform at least 100 to 200 procedures per year $(31,32)$ suggests that maintenance of competence requires continued experience in a clinical setting. Further study is needed to elucidate the specific factors responsible for failure to intubate the cecum, but for the present, the evaluation of reported cecal intubation rates is an important means of documenting technical skills for colonoscopy.

For this reason, it is important that endoscopists are able to recognize cecal landmarks reliably; trainees, for example, have been shown to significantly overestimate the achievement of cecal intubation (10). In this context, photodocumentation of cecal intubation is particularly important, both for clinical practice and for documentation of the endoscopist's colonoscopy completion rates. Visualization of the cecum should be noted, at a minimum, by documenting the identification of appropriate landmarks (eg, appendiceal orifice, ileocecal valve or terminal ileal mucosa) and, if possible, by photodocumentation. Unfortunately, photodocumentation equipment is not available in many endoscopy units, and if it is available, there are no formal image storage protocols. Nonetheless, visualization of landmarks should ideally be documented for every procedure (3).

Ileal intubation rates: With practice, ileal intubation can be achieved in $80 \%$ to $85 \%$ of colonoscopies $(21,33,34)$, but an $85 \%$ success rate may not be achieved until the endoscopist has performed 600 procedures (21). The average time required for ileal intubation is approximately $3 \mathrm{~min}(20,21,33,34)$. Trainees are less likely to be successful, and even if they are successful, they can take up to twice as long to achieve ileal intubation.

Ileoscopy can improve the diagnostic yield of colonoscopy $(21,33)$, but this depends on the indication for the colonoscopy. In patients with colonic inflammatory bowel disease, the diagnostic yield from ileal histology is $19 \%$, compared 
with $0.5 \%$ to $7.4 \%$ in unselected colonoscopy patients $(21,34,35)$. One study suggested that the diagnostic findings at ileal intubation alter patient management in only $50 \%$ of the patients (35). Therefore, ileal intubation is recommended only if there is a specific indication for inspecting the ileum and if the finding will alter management (35).

Adenoma detection rates: Studies show that screening colonoscopy in healthy, asymptomatic patients should detect adenomas in at least $25 \%$ of men and $15 \%$ of women who are older than 50 years of age $(3,16)$. Documentation of polyp miss rates and subsequent cancer development after screening colonoscopies is an important clinical outcome in the assessment of colonoscopy quality. Studies in the mid-1990s demonstrated miss rates for polyps during colonoscopy of $0 \%$ to $6 \%$ for adenomas $10 \mathrm{~mm}$ in size or larger, $12 \%$ to $13 \%$ for adenomas $6 \mathrm{~mm}$ to $9 \mathrm{~mm}$ in size, and $15 \%$ to $27 \%$ for adenomas $5 \mathrm{~mm}$ in size or smaller (36-38). Subsequent studies, using computed tomography, reported miss rates for conventional colonoscopy of $12 \%$ to $17 \%$ for adenomas $10 \mathrm{~mm}$ in size or larger $(39,40)$.

In clinical practice, polyp detection rates are quite variable, ranging from unacceptably low polyp yields to over-diagnosis of 'polyps', perhaps due to uncertainty as to what is normal and what is abnormal. In large surveys of colonoscopists in clinical practice, polyp detection rates of $0 \%$ to $60 \%$ have been reported $(14,36)$. Higher detection rates for polyps and adenomata are associated with longer examinations, longer withdrawal times $(17,18)$, more careful examination of the mucosa proximal to folds and flexures, better colonic distention, and better cleaning of debris and fluid from the colon (41).

Miss rates of $4 \%$ to $5 \%$ for colorectal cancer have been reported for colonoscopy $(42,43)$. One study reported that colon cancer was found in $6 \%$ of patients within three years of a screening colonoscopy (44). Right-sided lesions are especially prone to being missed because of incomplete colonoscopy; again, a report that nongastroenterologists missed cancers more often than gastroenterologists (OR 5.36, 95\% CI 2.94 to 9.77) (45) suggests that experience may be an important determinant of a successful colonoscopy.

It is generally considered important that endoscopists be able to estimate polyp size accurately, to help to determine which polyps can be removed safely. Training with different sizes of ball bearings, visualized with the optical distortion of a colonoscope, has been shown to decrease the mean error of estimation from $28 \%$ to $8 \%$ (46). However, to date, there have been no studies documenting either the ability of trainees to accurately gauge the sizes of colonic polyps or the effect of accurate polyp size estimation on clinical outcomes.

Therapeutic interventions: Competence in colonoscopy requires the ability to perform appropriate diagnostic (biopsy) and therapeutic (eg, polypectomy) interventions. It is mandatory that a colonoscopist be able to remove polyps effectively and safely to minimize the need for a repeat procedure solely to provide therapy and hence to improve cost-effectiveness. The ASGE (8) and the Gastroenterological Society of Australia (13) recommend that practitioners complete at least 30 supervised, unassisted snare polypectomies as a threshold for competence.

The colonoscopist must be familiar with electrocautery, the settings required, and any changes in settings or technique that may be required for different parts of the colon (ie, special precautions for the right colon) and for polyps of different sizes or shapes. The removal of large polyps, particularly those with sessile growth patterns, from high-risk locations in the colon is a skill that is acquired incrementally and likely requires experience with more than 30 polypectomies. Under these circumstances, the colonoscopist must be able to exercise clinical judgment, based on the polyp characteristics, to determine whether a separate consent process is needed, including a discussion of higher than average risks and surgical alternatives. Endoscopic hemostasis skills are also mandatory to immediately treat any peri- or postpolypectomy bleeding that may occur. Although uncommon, these therapeutic interventions can be very challenging, and exposure to these cases is critical in training.

Colonoscopists should also know when and how to perform biopsies. This knowledge should include the cognitive component of determining the indications for biopsy, in addition to the technical skills required to obtain targeted mucosal biopsies. Mucosal biopsies should be obtained from the colon and, possibly, from the terminal ileum in patients with chronic diarrhea (3), even if the mucosa is macroscopically normal, as is the case for patients with microscopic colitis (3). If surveillance is performed in patients with inflammatory bowel disease, systematic biopsy of the colon and terminal ileum can assist in establishing the extent of disease, as well as in differentiating between ulcerative colitis and Crohn's colitis. A systematic biopsy protocol increases the sensitivity of surveillance for dysplasia (47); as such, it should provide biopsies from all four quadrants, every $10 \mathrm{~cm}$ along the length of the colon (3).

\section{Complication rates}

The incidence of complications, such as perforation and postpolypectomy bleeding, recorded by an individual endoscopist should be comparable to those reported in the literature. The published evidence suggests that perforation rates should be less than one in 500 for all patients and less than one in 1000 for patients undergoing screening (48-50). The expected perforation rates for patients undergoing screening are lower because these individuals are generally healthy and they tend to not have colonic conditions that have been associated with perforation (3). Furthermore, the complication rates should be lower, because the risk to benefit ratio should also be lower for patients who are otherwise healthy.

Large epidemiological studies $(31,48)$ have not confirmed a statistical correlation between the rate of perforations and the level of experience, the number of prior colonoscopies or the annual volume of colonoscopies. This may be due, in part, to the low rate of complications, which makes it difficult to show statistical differences between groups. For example, a review (48) of over 10,000 colonoscopies reported that although trainees performed only $20 \%$ of procedures, they were involved in $40 \%$ of the perforations; however, this difference was not statistically significant.

Pseudo-obstruction, ischemia, severe colitis, radiationinduced changes, stricture formation, bulky colorectal cancers, severe diverticular disease and chronic corticosteroid therapy have been associated with higher rates of perforations (3).

Endoscopic series suggest that the overall risk for postpolypectomy bleeding should be less than $1 \%$ (51-55). The risk of bleeding increases with the size of the polyps and with a more proximal colonic location. Bleeding rates may exceed $10 \%$ for polyps larger than $2 \mathrm{~cm}$, particularly in the proximal colon (54-57). The use of blended or cutting diathermy current 
is associated with an increased risk of immediate bleeding, whereas pure low-power coagulation is associated with an increased risk of delayed bleeding $(58,59)$.

\section{TRAINING}

The proportion of colonoscopists in Canada or the United States that have had limited or no formal colonoscopy training is unknown. In a British study (24), 17\% of colonoscopists had received no supervised training for their first 100 procedures, and only $39 \%$ had been involved in a training course; the quality assessment demonstrated that cecal intubation was achieved in only $77 \%$ of cases. In Canada, all gastroenterologists are required to complete a formal two-year subspecialty training program, and many complete a third year of subspecialty training before they enter full-time practice. Surgical residents generally acquire their endoscopic and medical gastroenterology training over a shorter period of time, usually in the context of a three-month attachment to a gastroenterology training program.

The ASGE recommends that endoscopists complete a gastroenterology or surgical residency to satisfy the intellectual requirements regarding colonoscopy. Therefore, physicians in other specialties need the opportunity to acquire specialized knowledge in addition to technical training. The time needed for training of nonendoscopist physicians (nongastroenterologists and nonsurgeons) has not been clearly defined, but it must be sufficient to afford adequate exposure to the clinical assessment of inpatients and outpatients, as well as the opportunity to assimilate the relevant literature to fulfil the intellectual training requirements for colonoscopy. It is difficult to provide this extent of training in less than six to 12 months, even in a recognized teaching facility.

The ASGE recommends that the thresholds for determining endoscopic competence should be equivalent for nonphysician and physician trainees (60); therefore, it is reasonable that 'nonendoscopist physicians' should be expected to achieve the same standards of competence.

\section{Short courses}

Because neither the technical nor intellectual requirements for colonoscopy can be acquired in a short period of time, neither short courses nor self-instruction is considered to provide sufficient training to achieve competence in colonoscopy.

\section{Computer simulators}

Despite marked advances in computer graphics and tactile feedback (variable resistance of insertion, loop formation), the role of colonoscopic simulators remains unclear. Systems that are currently state-of-the-art (eg, GI Mentor and GI Mentor II, Symbionix, Israel) can distinguish between an experienced endoscopist and a beginner by procedure time and efficiency (ie, percentage of mucosa surveyed per second) (61). However, in one study, although experienced colonoscopists advanced much more quickly than novices on the simulator, the timeto-cecum appeared to plateau after only seven repetitions by medical students who had never previously performed an endoscopy (62), suggesting that current simulators do not provide a 'true-to-life' experience. On the other hand, there was no improvement or 'learning' of the program or procedure over five repetitions in another study that used a different simulator (HT Immersion Medical Colonoscopy Simulator, Immersion Medical, USA) (63). A study showing that simulator-trained fellows had higher cecal intubation rates than nontrained fellows for the first 15 human procedures (64), suggests that there may be benefit, at least at the outset, for simulator training; however, the long-term effect of simulator traning on competence for colonoscopy is not known. These caveats notwithstanding, it is probably preferable if novice endoscopists acquire their basic technical skills on a simulator rather than in a routine clinical setting; the longterm benefits may be limited, but the short-term benefits for the trainees' first few patients, the supervisor and, indeed, the trainee may be substantial.

\section{Proctoring}

A proctor is an impartial, qualified colonoscopist in charge of supervising a candidate during colonoscopy to assess competence. The role of the proctor is to evaluate - not to teach and not to help with the procedure (1). When appropriate, proctoring should extend over at least 30 to 50 supervised procedures, because it is very difficult to ascertain true failure and complication rates if fewer procedures are observed. However, it should be noted that proctoring is time-consuming; supervision of 30 to 50 procedures probably necessitates a time commitment of $25 \mathrm{~h}$ to $40 \mathrm{~h}$, and without appropriate compensation for the proctor, this cannot constitute a standard component of credentialing for colonoscopy.

\section{NONPHYSICIANS AND COLONOSCOPY}

The concept of well-trained nurses performing flexible sigmoidoscopy has been studied in the United Kingdom and the United States; this practice will be reviewed in a separate publication. For colonoscopy, the data on nurse-colonoscopists are much more limited. Although, anecdotally, nursecolonoscopists trained in the United Kingdom are at least the equal of physician colonoscopists, there are no nonphysician colonoscopy training programs in Canada at the present time. As a result, the CAG does not recommend that the present credentialing guidelines be applied in the case of nonphysicians who wish to undertake colonoscopy training. Clearly, all colonoscopists are expected to achieve the same standard of competence, but the training and documentation needed to achieve these standards may vary depending on the individual's initial level of training.

\section{SUMMARY}

Technical competence for routine colonoscopy can be assessed after 150 procedures; however, completion of a specified number of colonoscopies does not imply competence. It is recommended that documentation of competence be based on the completion of at least 100 unassisted procedures. Competent colonoscopists should be able to intubate the cecum in at least $85 \%$ to $90 \%$ of all cases $(3,13,22)$ and in at least $95 \%$ of screening cases in healthy adults (3). The mean completion time for colonoscopy should be approximately $30 \mathrm{~min}$, with an emphasis on methodical, careful withdrawal to optimize lesion detection. However, it should be recognized that some procedures may take more than $30 \mathrm{~min}$, particularly if multiple or complex polypectomies are required. The proposal that withdrawal times should generally be in excess of $7 \mathrm{~min}(16-18)$ emphasizes the importance of careful inspection on withdrawal of the colonoscope, although the optimal time has not been determined. Success rates improve with experience and higher 
annual procedure volume (31), particularly in the early years after completion of training (32). Better results have been associated with a volume of at least 100 to 200 procedures per year $(31,32)$. Photodocumentation of cecal intubation is encouraged for quality assurance purposes, to prompt appropriate ancillary investigations in the event of incomplete colonoscopy and to minimize the risk that right-sided lesions are missed.

When colonoscopy is performed for cancer screening, adenomata should be detected in at least 25\% of men and 15\% of women older than 50 years of age; lower detection rates raise the concern that polyps are being missed or that the procedure has been performed for an inappropriate indication (3). Competence in colonoscopy requires the ability to perform appropriate diagnostic and therapeutic interventions during the same procedure. At least 30 supervised, unassisted snare polypectomies should be completed as a threshold for competency $(8,13)$.

Complication rates should be comparable with those reported in the literature, that is, a perforation rate of less than one in 500 for all patients and less than one in 1000 for patients undergoing screening (48-50), with a postpolypectomy bleeding rate of less than $1 \%(51-55)$.

Nontechnical components of competence (knowledge of expected pathology, judgment regarding biopsy and therapy,

\section{REFERENCES}

1. Armstrong D, Enns R, Ponich T, Romagnuolo J, Springer J, Barkun AN. Canadian credentialing guidelines for endoscopic privileges: An overview. Can J Gastroenterol 2007;21:797-801.

2. Appropriate use of gastrointestinal endoscopy. American Society for Gastrointestinal Endoscopy. Gastrointest Endosc 2000;52:831-7.

3. Rex DK, Petrini JL, Baron TH, et al. Quality indicators for colonoscopy. Gastrointest Endosc 2006;63(Suppl 4):S16-28.

4. Balaguer F, Llach J, Castells A, et al. The European panel on the appropriateness of gastrointestinal endoscopy guidelines colonoscopy in an open-access endoscopy unit: A prospective study. Aliment Pharmacol Ther 2005;21:609-13.

5. Vader JP, Pache I, Froehlich F, et al. Overuse and underuse of colonoscopy in a European primary care setting. Gastrointest Endosc 2000;52:593-99.

6. de Bosset V, Froehlich F, Rey JP, et al. Do explicit appropriateness criteria enhance the diagnostic yield of colonoscopy? Endoscopy 2002;34:360-8

7. Sharma VK, Corder FA, Raufman JP, Sharma P, Fennerty MB, Howden CW. Survey of internal medicine residents' use of the fecal occult blood test and their understanding of colorectal cancer screening and surveillance. Am J Gastroenterol 2000;95:2068-73.

8. Eisen GM, Baron TH, Dominitz JA, et al, for the American Society for Gastrointestinal Endoscopy. Methods of granting hospital privileges to perform gastrointestinal endoscopy. Gastrointest Endosc 2002;55:780-3

9. Faigel DO, Baron TH, Lewis B, et al, for the ASGE Taskforce on Ensuring Competence in Endoscopy and the American College of Gastroenterology Executive and Practice Management Committees. Ensuring competence in endoscopy. <http://www.asge.org/WorkArea/showcontent.aspx?id=3384> (Version current at November 29, 2007).

10. Marshall JB. Technical proficiency of trainees performing colonoscopy: A learning curve. Gastrointest Endosc 1995;42:287-91.

11. Cass OW, Freeman ML, Peine CJ, Zera RT, Onstad GR. Objective evaluation of endoscopy skills during training. Ann Intern Med 1993;118:40-4.

12. Chak A, Cooper GS, Blades EW, Canto M, Sivak MV Jr. Prospective assessment of colonoscopic intubation skills in trainees. Gastrointest Endosc 1996;44:54-7.

13. Conjoint Committee for the Recognition of Training in Gastrointestinal Endoscopy. Information for registrants. indications, contraindications, informed consent and immediate postprocedural management) require a training program that generally involves a minimum of six to 12 months of training. Although endoscopic simulators may shorten the early phase of technical training, it is not clear how the rapid acquisition of apparent competence using a simulator translates into competence at colonoscopy in clinical practice.

Institutions that grant privileges for colonoscopy should be encouraged to develop endoscopic reporting mechanisms and databases so that colonoscopists may monitor the quality of their practice and effect improvements if they identify deficiencies, thus maintaining colonoscopic procedural competence and optimizing clinical care over the long term.

ACKNOWLEDGEMENTS: This manuscript was produced with the invaluable assistance of Pauline Lavigne, and the members of the Endoscopy Committee and Clinical Affairs Committee of the Canadian Association of Gastroenterology. At the time of submission, David Armstrong was head of the Endoscopy Committee and Alan Barkun was Chair of the Clinical Affairs Committee for the Canadian Association of Gastroenterology. The project was initiated and initial drafts were written by the Endoscopy Committee under past head, Dr Robert Enns.

<http://conjoint.gesa.org.au/information.html> (Version current at November 29, 2007).

14. Hilsden RJ. Patterns of use of flexible sigmoidoscopy, colonoscopy and gastroscopy: A population-based study in a Canadian province. Can J Gastroenterol 2004;18:213-9.

15. Sanchez W, Harewood GC, Petersen BT. Evaluation of polyp detection in relation to procedure time of screening or surveillance colonoscopy. Am J Gastroenterol 2004;99:1941-5.

16. Barclay R, Vicari JJ, Doughty AS, Johanson JF, Greenlaw RL. Colonoscopic withdrawal times and adenoma detection during screening colonoscopy. N Engl J Med 2006;355:2533-41.

17. Simmons DT, Harewood GC, Baron TH, et al. Impact of endoscopist withdrawal speed on polyp yield: Implications for optimal colonoscopy withdrawal time. Aliment Pharmacol Ther 2006;24:965-71.

18. Chen SC, Rex DK. Endoscopist can be more powerful than age and male gender in predicting adenoma detection at colonoscopy. Am J Gastroenterol 2007;102:856-61.

19. McCashland T, Brand R, Lyden E, de Garmo P. The time and financial impact of training fellows in endoscopy. CORI Research Project. Clinical Outcomes Research Initiative. Am J Gastroenterol 2000;95:3129-32.

20. Israel DM, McLain BI, Hassall E. Successful pancolonoscopy and ileoscopy in children. J Pediatr Gastroenterol Nutr 1994;19:283-9.

21. Cherian S, Singh P. Is routine ileoscopy useful? An observational study of procedure times, diagnostic yield, and learning curve. Am J Gastroenterol 2004;99:2324-9.

22. Marshall JB, Barthel JS. The frequency of total colonoscopy and terminal ileal intubation in the 1990s. Gastrointest Endosc 1993;39:518-20.

23. Fasih T, Varma JS, Tabaqchali MA. Prospective audit of quality of colonoscopy in a surgical coloproctology unit. Surgeon 2004;2:107-11. (Erratum in 2004;2:170).

24. Bowles CJ, Leicester R, Romaya C, Swarbrick E, Williams CB, Epstein O. A prospective study of colonoscopy practice in the UK today: Are we adequately prepared for national colorectal cancer screening tomorrow? Gut 2004;53:277-83.

25. Winkleman BJ, Matthews DE, Wiebke EA. Colorectal cancer screening at a Veterans Affairs hospital. Am J Surg 2003;186:468-71.

26. Rodney WM, Dabov G, Orientale E, Reeves WP. Sedation associated with a more complete colonoscopy. J Fam Pract 1993;36:394-400. 
27. Hopper W, Kyker KA, Rodney WM. Colonoscopy by a family physician: A 9-year experience of 1048 procedures. J Fam Pract 1996;43:561-6.

28. Rodney WM, Dabov G, Cronin C. Evolving colonoscopy skills in a rural family practice: The first 293 cases. Fam Pract Res J 1993;13:43-52.

29. Parry BR, Williams SM. Competency and the colonoscopist: A learning curve. Aust N Z J Surg 1991;61:419-22.

30. Tassios PS, Ladas SD, Grammenos I, Demertzis K, Raptis SA. Acquisition of competence in colonoscopy: The learning curve of trainees. Endoscopy 1999;31:702-6.

31. Wexner SD, Garbus JE, Singh JJ, for the SAGES Colonscopy Study Outcomes Group. A prospective analysis of 13,580 colonoscopies. Reevaluation of credentialing guidelines. Surg Endosc 2001;15:251-61

32. Harewood GC. Relationship of colonoscopy completion rates and endoscopist features. Dig Dis Sci 2005;50:47-51.

33. Bhasin DK, Goenka MK, Dhavan S, Dass K, Singh K. Diagnostic value of ileoscopy: A report from India. J Clin Gastroenterol 2000;31:144-6.

34. Kundrotas LW, Clement DJ, Kubik CM, Robinson AB, Wolfe PA. A prospective evaluation of successful terminal ileum intubation during routine colonoscopy. Gastrointest Endosc 1994;40:544-6.

35. Yoong KK, Heymann T. It is not worthwhile to perform ileoscopy on all patients. Surg Endosc 2006;20:809-11.

36. Rex DK, Cutler CS, Lemmel GT, et al. Colonoscopic miss rates of adenomas determined by back-to-back colonoscopies. Gastroenterology 1997;112:24-8.

37. Hixson LJ, Fennerty MB, Sampliner RE, McGee D, Garewal H. Prospective study of the frequency and size distribution of polyps missed by colonoscopy. J Natl Cancer Inst 1990;82:1769-72.

38. Schoenfeld P, Lipscomb S, Crook J, et al. Accuracy of polyp detection by gastroenterologists and nurse endoscopists during flexible sigmoidoscopy: A randomized trial. Gastroenterology 1999;117:312-8

39. Pickhardt PJ, Nugent PA, Mysliwiec PA, Choi JR, Schindler WR. Location of adenomas missed by optical colonoscopy. Ann Intern Med 2004;141:352-9.

40. Van Gelder RE, Nio CY, Florie J, et al. Computed tomographic colonography compared with colonoscopy in patients at increased risk for colorectal cancer. Gastroenterology 2004;127:41-8.

41. Rex DK. Colonoscopic withdrawal technique is associated with adenoma miss rates. Gastrointest Endosc 2000;51:33-6.

42. Rex DK, Rahmani EY, Haseman JH, Lemmel GT, Kaster S, Buckly JS. Relative sensitivity of colonoscopy and barium enema for detection of colorectal cancer in clinical practice. Gastroenterology 1997;112:17-23.

43. Bressler B, Paszat LF, Vinden C, Li C, He J, Rabeneck L. Colonoscopic miss rates for right-sided colon cancer: A population-based analysis. Gastroenterology 2004;127:452-6.

44. Hosokawa O, Shirasaki S, Kaizaki Y, Hayashi H, Douden K, Hattori M. Invasive colorectal cancer detected up to 3 years after a colonoscopy negative for cancer. Endoscopy 2003;35:506-10.

45. Haseman JH, Lemmel GT, Rahmani EY, Rex DK. Failure of colonoscopy to detect colorectal cancer: Evaluation of 47 cases in 20 hospitals. Gastrointest Endosc 1997;45:451-5.
46. Schwartz E, Catalano MF, Krevsky B. Endoscopic estimation of size: Improved accuracy by directed teaching. Gastrointest Endosc 1995:42:292-5.

47. Rubin CE, Haggitt RC, Burmer GC, et al. DNA aneuploidy in colonic biopsies predicts future development of dysplasia in ulcerative colitis. Gastroenterology 1992;103:1611-20.

48. Anderson ML, Pasha TM, Leighton JA. Endoscopic perforation of the colon: Lessons from a 10-year study. Am J Gastroenterol 2000;95:3418-22.

49. Rex DK, Bond JH, Winawer S, et al, for the U.S. Multi-Society Task Force on Colorectal Cancer. Quality in the technical performance of colonoscopy and the continuous quality improvement process for colonoscopy: Recommendations of the U.S. Multi-Society Task Force on Colorectal Cancer. Am J Gastroenterol 2002;97:1296-308.

50. Gatto NM, Frucht H, Sundararajan V, Jacobson JS, Grann VR, Neugut AI. Risk of perforation after colonoscopy and sigmoidoscopy: A population-based study. J Natl Cancer Inst 2003;95:230-6.

51. Fruhmorgen P, Demling L. Complications of diagnostic and therapeutic colonoscopy in the Federal Republic of Germany. Results of an inquiry. Endoscopy 1979;11:146-50.

52. Nivatvongs S. Complications in colonoscopic polypectomy. An experience with 1,555 polypectomies. Dis Colon Rectum 1986;29:825-30

53. Silvis SE, Nebel O, Rogers G, Sugawa C, Mandelstam P. Endoscopic complications. Results of the 1974 American Society for Gastrointestinal Endoscopy Survey. JAMA 1976;235:928-30.

54. Zubarik R, Fleischer DE, Mastropietro C, et al. Prospective analysis of complications 30 days after outpatient colonoscopy. Gastrointest Endosc 1999;50:322-8.

55. Sorbi D, Norton I, Conio M, Balm R, Zinsmeister A, Gostout CJ. Postpolypectomy lower GI bleeding: Descriptive analysis. Gastrointest Endosc 2000;51:690-6.

56. Waye JD. Saline injection colonoscopic polypectomy. Am J Gastroenterol 1994;89:305-6.

57. Hurlstone DP, Sanders DS, Cross SS, et al. Colonoscopic resection of lateral spreading tumours: A prospective analysis of endoscopic mucosal resection. Gut 2004;53:1334-9.

58. Van Gossum A, Cozzoli A, Adler M, Taton G, Cremer M. Colonoscopic snare polypectomy: Analysis of 1485 resections comparing two types of current. Gastrointest Endosc 1992;38:472-5.

59. Parra-Blanco A, Kaminaga N, Kojima T, Endo Y, Tajiri A, Fujita R. Colonoscopic polypectomy with cutting current: Is it safe? Gastrointest Endosc 2000;51:676-81.

60. Endoscopy by non-physicians: Guidelines for clinical application. From the ASGE. American Society for Gastrointestinal Endoscopy. Gastrointest Endosc 1999;49:826-8.

61. Felsher JJ, Olesevich M, Farres H, et al. Validation of a flexible endoscopy simulator. Am J Surg 2005;189:497-500.

62. Eversbusch A, Grantcharov TP. Learning curves and impact of psychomotor training on performance in simulated colonoscopy: A randomized trial using a virtual reality endoscopy trainer. Surg Endosc 2004;18:1514-8.

63. Mahmood T, Darzi A. The learning curve for a colonoscopy simulator in the absence of any feedback: No feedback, no learning. Surg Endosc 2004;18:1224-30.

64. Sedlack RE, Kolars JC. Computer simulator training enhances the competency of gastroenterology fellows at colonoscopy: Results of a pilot study. Am J Gastroenterol 2004;99:33-7. 


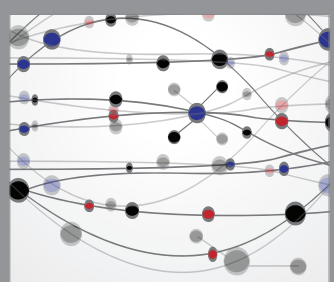

The Scientific World Journal
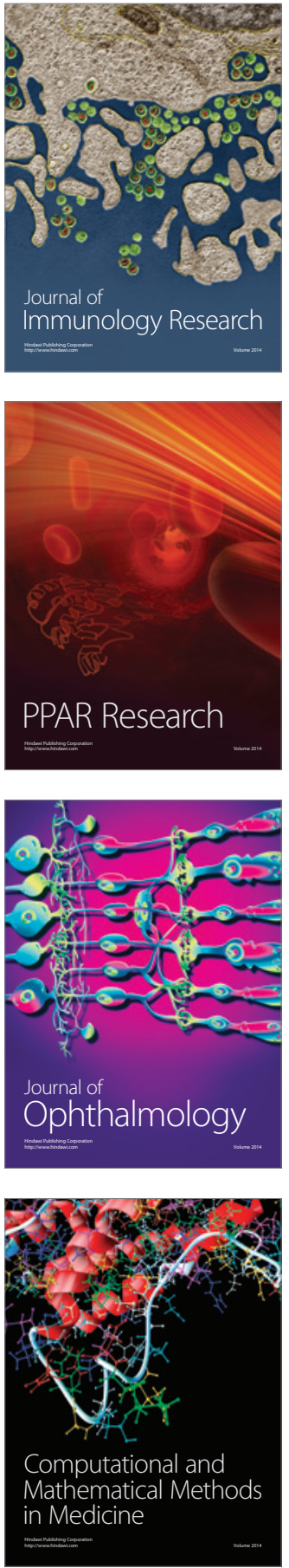

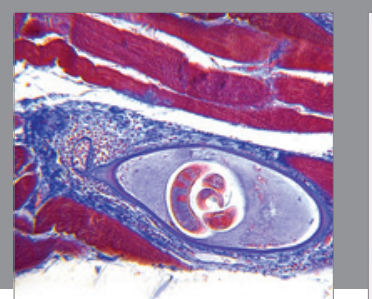

Gastroenterology Research and Practice

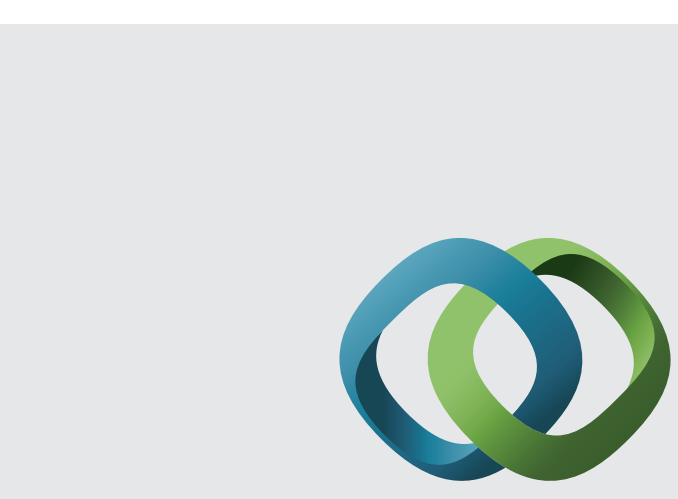

\section{Hindawi}

Submit your manuscripts at

http://www.hindawi.com
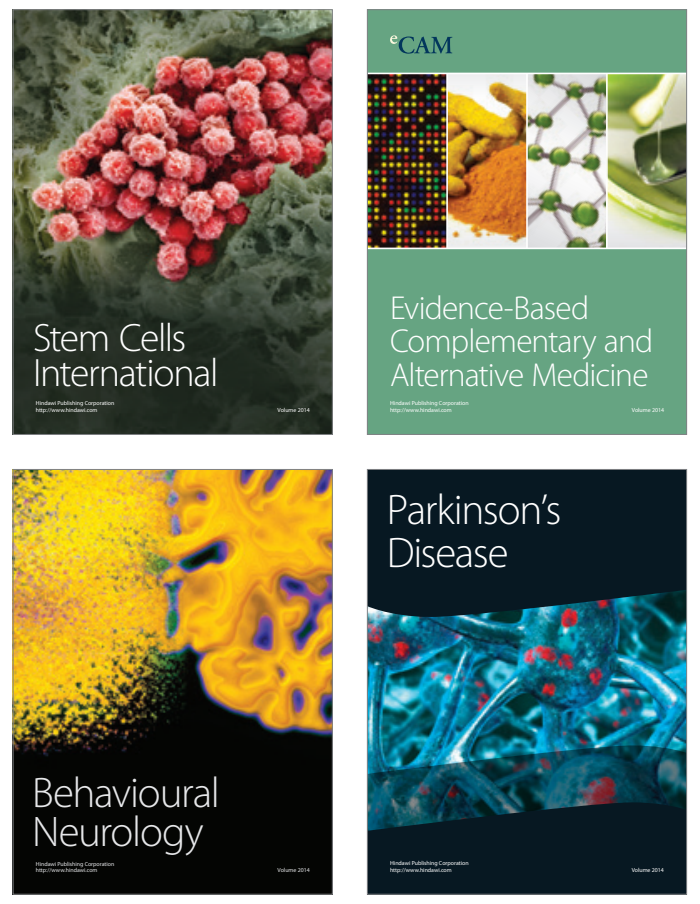
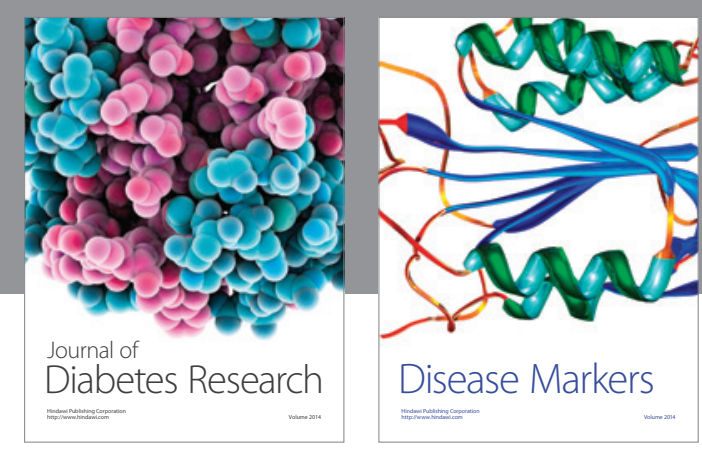

Disease Markers
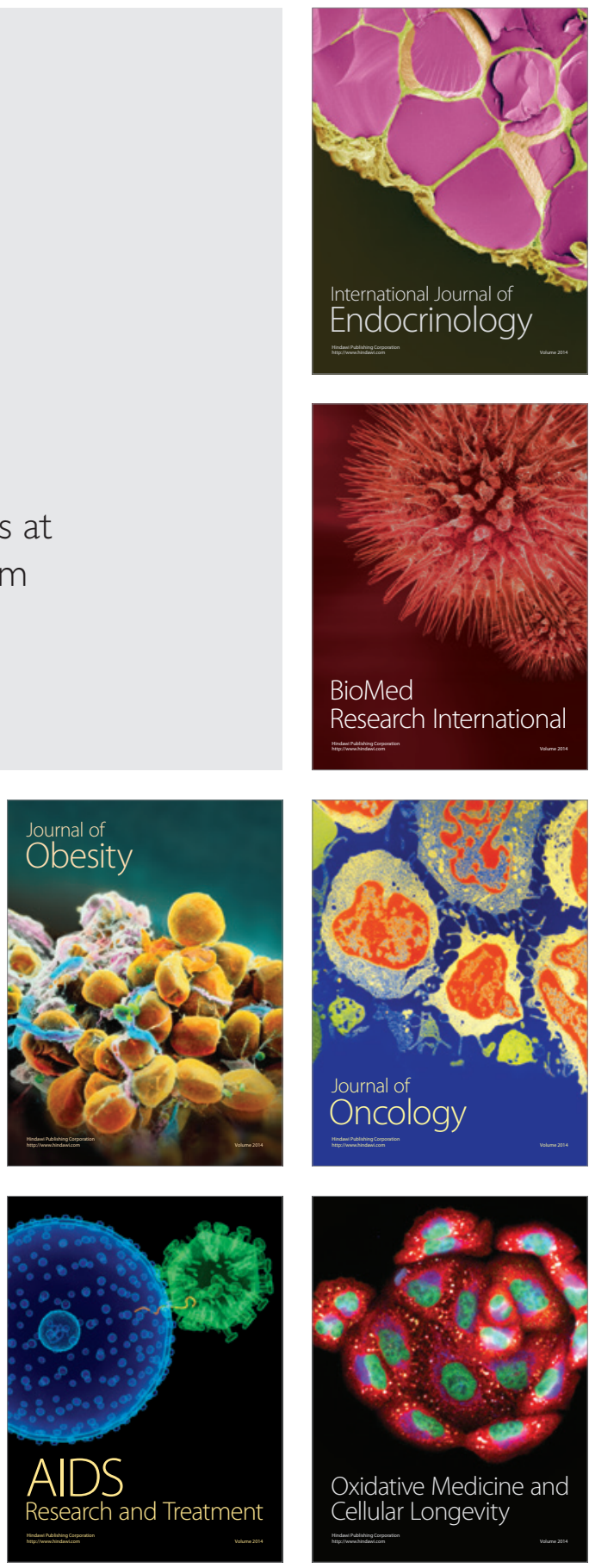